\title{
Treatment of Coronavirus Disease 2019 (COVID-19) Patients with Convalescent Plasma
}

Eric Salazar, ${ }^{* \dagger}$ Katherine K. Perez, ${ }^{\star}{ }^{\ddagger}$ Madiha Ashraf, ${ }^{\S}$ Jian Chen, ${ }^{*}$ Brian Castillo, ${ }^{*}$ Paul A. Christensen, ${ }^{*}$ Taryn Eubank, David W. Bernard, ${ }^{* \dagger}$ Todd N. Eagar, ${ }^{* \dagger}$ S. Wesley Long, ${ }^{*}{ }^{*}$ Sishir Subedi, ${ }^{*}$ Randall J. Olsen, ${ }^{* \dagger}$ Christopher Leveque, ${ }^{*}$ Mary R. Schwartz, * Monisha Dey, ${ }^{*}$ Cheryl Chavez-East, * John Rogers, * Ahmed Shehabeldin, * David Joseph, * Guy Williams, * Karen Thomas, ${ }^{*}$ Faisal Masud, ${ }^{\S \|}$ Christina Talley, ${ }^{* *}$ Katharine G. Dlouhy, ${ }^{* *}$ Bevin V. Lopez, ${ }^{* *}$ Curt Hampton, ** Jason Lavinder, ${ }^{\dagger \dagger}$ Jimmy D. Gollihar, ${ }^{\S \S}$ Andre C. Maranhao, ${ }^{\dagger \dagger}$ Gregory C. Ippolito, ${ }^{\dagger \dagger \dagger}$ Matthew 0. Saavedra, ${ }^{\natural}$

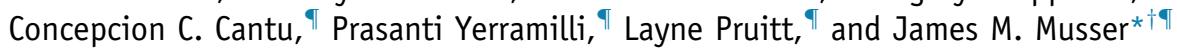

From the Departments of Pathology and Genomic Medicine, ${ }^{*}$ Pharmacy, ${ }^{\ddagger}$ and Anesthesiology and Critical Care ${ }^{\|}$and the Division of Infectious Diseases, ${ }^{\S}$ Department of Clinical Medicine, Houston Methodist Hospital, Houston, Texas; the Department of Pathology and Laboratory Medicine, ${ }^{\dagger}$ Weill Cornell Medical College, New York, New York; the Center for Molecular and Translational Human Infectious Diseases and the Academic Office of Clinical Trials, ** Houston Methodist Research Institute, Houston, Texas; the Departments of Molecular Biosciences ${ }^{\dagger \dagger}$ and Oncology, ${ }^{\ddagger \ddagger}$ Dell Medical School, University of Texas at Austin, Austin, Texas; and the Combat Capabilities Development Command (CCDC) Army Research Laboratory-South, ${ }^{\S \S}$ University of Texas at Austin, Austin, Texas

Accepted for publication

May 21, 2020.

Address correspondence to James M. Musser, M.D., Ph.D., Houston Methodist Hospital, 6565 Fannin St., B490, Houston, TX 77030. E-mail: jmmusser@houstonmethodist. org.
Coronavirus disease 2019 (COVID-19), caused by severe acute respiratory syndrome coronavirus 2, has spread globally, and no proven treatments are available. Convalescent plasma therapy has been used with varying degrees of success to treat severe microbial infections for $>100$ years. Patients $(n=25)$ with severe and/or life-threatening COVID-19 disease were enrolled at the Houston Methodist hospitals from March 28, 2020, to April 14, 2020. Patients were transfused with convalescent plasma, obtained from donors with confirmed severe acute respiratory syndrome coronavirus 2 infection who had recovered. The primary study outcome was safety, and the secondary outcome was clinical status at day 14 after transfusion. Clinical improvement was assessed on the basis of a modified World Health Organization six-point ordinal scale and laboratory parameters. Viral genome sequencing was performed on donor and recipient strains. At day 7 after transfusion with convalescent plasma, nine patients had at least a one-point improvement in clinical scale, and seven of those were discharged. By day 14 after transfusion, $19(76 \%)$ patients had at least a one-point improvement in clinical status, and 11 were discharged. No adverse events as a result of plasma transfusion were observed. Whole genome sequencing data did not identify a strain genotype-disease severity correlation. The data indicate that administration of convalescent plasma is a safe treatment option for those with severe COVID-19 disease. (Am J Pathol 2020, 190: 1680-1690; https://doi.org/10.1016/j.ajpath.2020.05.014)
The coronavirus disease 2019 (COVID-19) pandemic has spread globally and caused massive loss of life and economic hardship. As of May 2, 2020, there were 3,494,671 confirmed cases and 246,475 deaths worldwide, and in the United States, there were 1,154,340 confirmed cases and 67,447 deaths (Johns Hopkins University, https://coronavirus.jhu.edu/map. html, last accessed May 2, 2020). The disease is caused by severe acute respiratory syndrome coronavirus 2 (SARS-CoV-2), a highly transmissible coronavirus first identified in Wuhan, China. ${ }^{1-3}$ SARS-CoV-2 continues to spread in many countries, ${ }^{4-8}$ and despite aggressive research, no proven therapies have been described.

Treatment strategies for critically ill COVID-19 patients are lacking, with only limited evidence available for a

Supported by NIH grants AI146771-01 and AI139369-01; the Fondren Foundation, Houston Methodist Hospital and Research Institute (J.M.M.); National Institute of Allergy and Infectious Diseases/NIH, contract 75N93019C00050 (J.L. and G.C.I.); and Army Research Office Cooperative Agreement W911NF-12-1-0390 (J.D.G.).

Disclosures: None declared. 
battery of antiviral, antibiotic, and anti-inflammatory agents, and aggressive supportive therapy. Multiple clinical trials are ongoing, including the repurposing of remdesivir, an antiviral agent investigated to treat Ebola, and hydroxychloroquine, an antimalarial chloroquine derivative used to treat lupus and rheumatoid arthritis. There are early anti-COVID-19 efficacy data with remdesivir. ${ }^{9}$ Preliminary data supporting the use of hydroxychloroquine, alone or in combination with azithromycin, ${ }^{10}$ have since been shown by larger controlled trials as misleading and potentially dangerous. ${ }^{11}$ New therapies are needed to improve outcomes for critically ill COVID-19 patients.

In convalescent plasma therapy, blood plasma from a recovered patient is collected and transfused to a symptomatic patient. The transfer of convalescent plasma is an old concept, having been used since at least 1918 when it was employed to fight the Spanish flu pandemic. ${ }^{12}$ More recently, convalescent plasma was used with some reported success during the 2003 SARS pandemic, ${ }^{13,14}$ the 2009 influenza H1N1 pandemic, ${ }^{15}$ and the 2015 Ebola outbreak in Africa. ${ }^{16}$ Several small observational studies published during the COVID-19 pandemic suggest convalescent plasma is part of an effective treatment strategy for patients with severe disease. ${ }^{17-20}$ The first report describing administration of convalescent plasma to five patients early in the COVID-19 outbreak in Wuhan was recently published. ${ }^{18}$ Five critically ill patients received two, same-day infusions from five recovered healthy donors. In four of the five patients, inflammatory biomarkers decreased and Alveolar-arterial (A/a) gradient improved, and all patients had improvement in pulmonary lesions on the basis of computed tomography scan. ${ }^{18}$ A second study by Duan et $\mathrm{al}^{17}$ reported improved clinical outcomes in 10 patients who received a single transfusion of convalescent plasma, with no adverse events reported. Two additional small case studies of five and six patients have since been published with similar findings. ${ }^{19,20}$ A more recent study by Zeng et $\mathrm{al}^{21}$ suggested that administration of convalescent plasma late in the disease course was ineffective for mortality reduction.

We performed the present study to provide additional data on these initial clinical observations of patients' clinical course and subsequent improvement after receiving convalescent plasma therapy for COVID-19. We transfused 25 COVID-19 patients with severe and/or life-threatening disease at the Houston Methodist hospitals, a large, quaternarycare hospital system that serves metropolitan Houston, TX (approximately 7 million people; United States Census Bureau, https://www.census.gov/newsroom/press-kits/2020/ pop-estimates-county-metro.html, last accessed May 3, 2020). Patients were transfused once with $300 \mathrm{~mL}$ of convalescent plasma. The therapy was well tolerated, and no transfusion-related adverse events were observed. At day 7 after transfusion, 9 of 25 patients (36\%) had improvement in the assessed clinical end points. By 14 days after transfusion, 19 patients (76\%) had improved or been discharged. Although this study has limitations, the data indicate that transfusion of convalescent plasma is a safe treatment option for those with severe COVID-19 disease.

\section{Materials and Methods}

This study was conducted at the Houston Methodist hospitals from March 28, 2020, through April 28, 2020, with the approval of the Houston Methodist Research Institute ethics review board and with informed patient or legally authorized representative consent. Patients were treated under either emergency investigational new drug or investigational new drug applications, approved by the US Food and Drug Administration (https://www.fda.gov/ medical-devices/emergency-situations-medical-devices/ emergency-use-authorizations, last accessed May 3, 2020). Approval to treat the first patient by emergency investigational new drug was granted on March 28, 2020. The investigational new drug application was approved on April 3, 2020.

\section{Patients}

COVID-19 patients in the Houston Methodist hospitals were considered for enrollment in this trial. SARS-CoV-2 infection was confirmed by reverse transcriptase real-time PCR. Patients were eligible if they had severe and/or life-threatening COVID19 disease (US Food and Drug Administration, https://www. fda.gov/vaccines-blood-biologics/investigational-new-drugind-or-device-exemption-ide-process-cber/recommendationsinvestigational-covid-19-convalescent-plasma\#Patient\%20 Eligibility2020, last accessed May 3, 2020). Severe disease was defined as one or more of the following: shortness of breath (dyspnea), respiratory rate $\geq 30 / \mathrm{min}$, blood oxygen saturation $\leq 93 \%$, partial pressure of arterial oxygen to fraction of inspired oxygen ratio $<300$, and/or pulmonary infiltrates $>50 \%$ within 24 to 48 hours. Life-threatening disease was defined as one or more of the following: respiratory failure, septic shock, and/or multiple organ dysfunction or failure. Clinical data for patients were obtained from the hospital electronic medical record.

\section{Definition of Clinical Disease Severity}

Clinical severity for the purposes of outcome assessment was scored on the basis of a modified six-point clinical scale used by the World Health Organization Research and Development Blueprint group (https://www.who.int) blueprint/priority-diseases/key-action/COVID-19_Treatment_ Trial_Design_Master_Protocol_synopsis_Final_18022020.pdf, last accessed May 6, 2020). Patients were assigned a clinical status at baseline (day 0 , date of transfusion) and evaluated at days 0,7 , and 14. The six-point scale is as follows: 1, discharged (alive); 2, hospitalized, not requiring supplemental oxygen but requiring ongoing medical care (for 
COVID-19 or otherwise); 3, hospitalized, requiring lowflow supplemental oxygen; 4, hospitalized, on noninvasive ventilation or high-flow oxygen devices; 5 , hospitalized and on invasive mechanical ventilation or extracorporeal membrane oxygenation (ECMO); and 6, death.

\section{Convalescent Plasma Donors}

Convalescent plasma was obtained by apheresis using the Trima Accel automated blood collection system (Terumo BCT, Lakewood, CO). Plasma $(600 \mathrm{~mL})$ was collected from each donor and divided into two 300-mL units. Each donor had a documented history of laboratory-confirmed SARS-CoV-2 infection on the basis of a positive RT-PCR test result. All plasma was donated by recovered and healthy COVID-19 patients who had been asymptomatic for $\geq 14$ days. Donors were between 23 and 67 years old. All donors provided written informed consent and tested negative for SARS-CoV-2 by RTPCR. If eligible according to standard blood donor criteria, donors were enrolled in a frequent plasmapheresis program. Donors were negative for anti-human leukocyte antigen antibodies, hepatitis B virus, hepatitis C virus, HIV, human Tlymphotropic virus I/II, Chagas disease, West Nile virus, Zika virus, and syphilis, per standard blood banking practices.

\section{RT-PCR Testing for SARS-CoV-2 Infection}

Symptomatic patients with a high degree of clinical suspicion for COVID-19 disease were tested in the Molecular Diagnostics Laboratory at Houston Methodist Hospital using a validated assay applied for under Emergency Use Authorization from the US Food and Drug Administration. The assay follows the protocol published by the World Health Organization ${ }^{22}$ and uses a 7500 Fast Dx instrument (Applied Biosystems, Foster City, CA) and 7500 SDS software version 1.4.1 (Applied Biosystems). Testing was performed on nasopharyngeal or oropharyngeal swabs immersed in universal transport media, bronchoalveolar lavage fluid, or sputum treated with dithiothreitol.

\section{SARS-CoV-2 Spike Protein RBD and ECD Domains}

\section{Expression}

The expression and purification of the receptor binding domain (RBD) and ectodomain (ECD) of the SARS-CoV-2 spike protein have been described previously. ${ }^{23}$ Briefly, the RBD (residues 319 to 591) and ECD (residues 1 to 1208) domains were cloned into the mammalian expression vector $\mathrm{p} \alpha \mathrm{H}$ (pNCOV-1), which contains an HRV3C cleavage site upstream of TwinStrep and 8xHis purification tags. The ColE1 vector was transformed and maintained in Escherichia coli $\mathrm{DH} 10 \mathrm{~B}$ at $37^{\circ} \mathrm{C}$ using ampicillin selection at $100 \mu \mathrm{g} / \mathrm{mL}$. Plasmids from single colonies were recovered using a mini-prep kit (Qiagen, Germantown, MD) after growing cells overnight in Superior broth (AthenaES, Baltimore, MD) supplemented with $100 \mu \mathrm{g} / \mathrm{mL}$ ampicillin.

\section{Purification}

Expi293F cells (Thermo Fisher, Waltham, MA) were passaged twice and seeded to a density of $7.5 \times 10^{7}$ cells in $25.5 \mathrm{~mL}$ Expi293 Expression Medium $\left(2.9 \times 10^{6}\right.$ cells $/ \mathrm{mL}$ in a $125-\mathrm{mL}$ flask). For each 30-mL transfection, plasmid DNA (30 $\mu \mathrm{g}$; a gift from Dr. Jason S. McLellan, The University of Texas at Austin, Austin, TX) was added to Opti-MEM I Reduced Serum Medium (Gibco, Gaithersburg, MD) to a total volume of 1.5 $\mathrm{mL}$ and gently mixed. ExpiFectamine 293 Reagent $(81 \mu \mathrm{L})$ was diluted in Opti-MEM I medium to a total volume of 1.5 $\mathrm{mL}$. After gently mixing, it was incubated for 5 minutes at room temperature. After incubation, the diluted DNA was added to the diluted ExpiFectamine 293 Reagent to obtain a total volume of $3 \mathrm{~mL}$ and gently mixed. The mixture was incubated for 20 minutes at room temperature to allow the DNA-ExpiFectamine 293 Reagent complexes to form and then added to the Expi293F cells. After incubating cells for 20 hours, $150 \mu \mathrm{L}$ of ExpiFectamine 293 Transfection Enhancer 1 and $1.5 \mathrm{~mL}$ of ExpiFectamine 293 Transfection Enhancer 2 were added to each flask. Cells were harvested at 7 days.

\section{Protein Purification}

Immobilized metal affinity chromatography purification columns were used with $1 \mathrm{~mL}$ bed volume for each Ni-NTA column. Each prepared column was used to purify proteins from 200 to $250 \mathrm{~mL}$ of filtered tissue culture media. Following filtration, filtered tissue culture medium was applied to a previously prepared and equilibrated Ni-NTA column. Each column was washed with $20 \mathrm{~mL}$ equilibration buffer $(50 \mathrm{mmol} / \mathrm{L}$ phosphate buffer, $\mathrm{pH} 7.5,300 \mathrm{mmol} / \mathrm{L}$ $\mathrm{NaCl}$, and $20 \mathrm{mmol} / \mathrm{L}$ imidazole). The target protein was eluted with $5 \mathrm{~mL}$ elution buffer $(50 \mathrm{mmol} / \mathrm{L}$ phosphate buffer, $\mathrm{pH} 7.5,300 \mathrm{mmol} / \mathrm{L} \mathrm{NaCl}$, and $250 \mathrm{mmol} / \mathrm{L}$ imidazole). The eluate was applied to a spin concentrator with $100 \mathrm{kDa}$ molecular weight cutoff to concentrate target protein before fast protein liquid chromatography purification and for buffer exchange into cold $1 \times$ phosphatebuffered saline (PBS). Spin concentrators were centrifuged at $3000 \times g$, at $4^{\circ} \mathrm{C}$ for 15 minutes. Following buffer exchange, the eluate was concentrated to approximately 600 $\mu \mathrm{L}$. The concentrated eluate was further purified using sizeexclusion chromatography with a 24-mL Superose $610 / 300$ GL column (GE Healthcare, Chicago, IL). The $0.5-\mathrm{mL}$ sample loop was injected with $1 \mathrm{~mL}$ each of the following: $0.1 \mathrm{~mol} / \mathrm{L} \mathrm{NaOH}$, RNase-free water, and $1 \times$ PBS. The buffer-exchanged eluate was applied to the fast protein liquid chromatography sample loop and run with a flow rate $0.25 \mathrm{~mL} /$ minute. Fractions were collected after 0.2 $\mathrm{CV}$, and fractionation volumes were collected at $0.33 \mathrm{~mL}$.

\section{SARS-CoV-2 ELISA}

Costar 96-well assay plates (Corning, Corning, NY) were coated with either SARS-CoV-2 spike (S protein) ECD or SARS-CoV-2 spike RBD $(50 \mu \mathrm{L}$ at $2 \mu \mathrm{g} / \mathrm{mL}$ in PBS) 
overnight at $4{ }^{\circ} \mathrm{C}$. Plates were blocked with $2 \%$ milk in PBS at room temperature for 2 hours and washed $3 \times$ with PBS with $0.1 \%$ Tween 20 . Plasma or monoclonal antibody was serially diluted in $50 \mu \mathrm{L} /$ well across the entire 96-well plate. Negative plasma control was included on each antigen plate. Monoclonal antibody CR3022 (a gift from Dr. Jason S. McLellan) was used as a positive control. CR3022 is a neutralizing antibody originally cloned from a convalescent SARS patient that targets the RBD of SARS-CoV ${ }^{24}$ and binds to the RBD of SARS-CoV-2 with a binding affinity of $6.3 \mathrm{nmol} / \mathrm{L} .{ }^{25}$ Binding was performed at room temperature for 1 hour. Plates were washed, and anti-human IgG Fab HRP (Sigma A0293; 1:5000; Sigma-Aldrich, St. Louis, MO) was added to the plate $(50 \mu \mathrm{L})$ and incubated at room temperature for 30 minutes. Plates were washed $3 \times$ with PBS with $0.1 \%$ Tween 20, enzyme-linked immunosorbent assay (ELISA) substrate (1-step Ultra TMB; Thermo Fisher) was added, plates were developed for 1 minute for RBD and 5 minutes for spike ECD, and the reaction was stopped with $50 \mu \mathrm{L}$ of $\mathrm{H}_{2} \mathrm{SO}_{4}$. Plates were read at $450 \mathrm{~nm}$ absorbance. Threefold serial dilutions from 50 to 4050 were analyzed. Titer was defined as the last dilution showing an OD greater than a multiplate negative control average plus six SDs.

\section{SARS-CoV-2 Genome Sequencing and Analysis}

Libraries for whole viral genome sequencing were prepared according to version 1 ARTIC nCoV-2019 sequencing protocol (https://artic.network/ncov-2019, last accessed May 6, 2020). Long reads were generated with the LSK109 sequencing kit, 24 native barcodes (NBD104 and NBD114 kits), and a GridION instrument (Oxford Nanopore, Oxford, UK). Short reads were generated with the NexteraXT kit and a MiSeq or NextSeq 550 instrument (Illumina, San Diego, CA). Whole genome alignments of consensus viral genome sequence generated from the ARTIC nCoV-2019 bioinformatics pipeline were trimmed to the start of orf1ab and the end of orf10 and used to generate a phylogenetic tree using RAxML version 8 . 2 (https://cme.h-its.org/exelixis/web/software/raxml/index. html, last accessed May 3, 2020) ${ }^{26}$ to determine viral clade. Trees were visualized and annotated with CLC Genomics Workbench version 20 (Qiagen).

\section{Results}

\section{Overview of Patient Characteristics}

Twenty-five patients with severe and/or life-threatening COVID-19 disease were enrolled in the study from March 28, 2020, to April 14, 2020. Patients ranged in age from 19 to 77 years [median, 51 years; interquartile range (IQR), 42.5 to 60 years], and 14 were female (Table 1). The median body mass index was $30.4 \mathrm{~kg} / \mathrm{m}^{2}$ (IQR, 26.5 to $37 \mathrm{~kg} / \mathrm{m}^{2}$ ), and most $(22 / 25,88 \%)$ had no smoking history. Many patients $(16 / 25,64 \%)$ had one or more underlying chronic conditions, including diabetes mellitus (10 patients), hypertension (9 patients), hyperlipidemia (5 patients), and gastrointestinal reflux disease (4 patients). Most patients $(19 / 25,76 \%)$ enrolled in the study had O-positive blood type. Bacterial or viral co-infections were identified in five patients (Table 1).

\section{Donor Characteristics}

The characteristics of the donors of convalescent plasma are shown in Table 2. A total of nine donors provided plasma that was used to transfuse COVID-19 patients; two donors gave plasma on multiple occasions. The donors ranged in age from 23 to 67 years, and $56 \%$ (5/9) were males. On average, the donors gave plasma 26 days (range, 19 to 33 days) after their symptom start date and 21 days (range, 13 to 27 days) after their initial positive RT-PCR specimen collection date. Although all donors had been symptomatic, only one was ill enough to require hospitalization. To assess antibody titers, two ELISAs were used, one based on recombinant purified ECD of the spike protein and the second using recombinant RBD of the spike protein. The titers of the convalescent plasma used for transfusion ranged from 0 to 1350 for the RBD and ECD domains (Figure 1 and Supplemental Table S1).

\section{Transfusion of Severe COVID-19 Patients with Convalescent-Phase Donor Plasma}

The median time from symptom onset to hospitalization was 6 days (IQR, 4 to 8 days) (Table 3). Most patients received concomitant anti-inflammatory treatments within 5 days of the plasma transfusion, including tocilizumab and steroids. Most received other investigational treatments, including courses of hydroxychloroquine and azithromycin, ribavirin, and/or lopinavir/ritonavir; and two patients received remdesivir (Table 3). All patients required oxygen support before transfusion (Figure 1), including 12 patients on mechanical ventilation, 10 on low-flow oxygen, and 3 on high-flow oxygen. One patient (Patient 9) was placed on ECMO on the day of transfusion before transfusion. More than half (13/25, $52 \%$ ) had acute respiratory distress syndrome ${ }^{27}$ at the time of transfusion (Table 3). The median time from symptom onset to transfusion was 10 days (IQR, 7.5 to 12.5 days), and the median time from hospitalization to transfusion was 2 days (IQR, 2 to 4 days) (Table 3). All patients received one 300$\mathrm{mL}$ dose of convalescent-phase plasma, and one patient received a second transfusion 6 days after the initial transfusion. Clinical outcomes and laboratory parameters were assessed at days 0,7 , and 14 after transfusion.

\section{Outcomes}

The primary clinical end point of the study was safety. No adverse events attributed to plasma transfusion occurred within 24 hours after transfusion. One patient developed a 
Table 1 Demographics and Clinical Characteristics of Patients with COVID-19 Disease Who Received Convalescent Plasma

\begin{tabular}{|c|c|c|c|c|c|c|c|c|}
\hline Patient & Sex & $\begin{array}{l}\text { Age, } \\
\text { years }\end{array}$ & Weight, kg & BMI, $\mathrm{kg} / \mathrm{m}^{2}$ & $\begin{array}{l}\text { Smoking } \\
\text { history }\end{array}$ & Blood type & Co-infections & Co-existing chronic diseases \\
\hline 1 & $\mathrm{~F}$ & 39 & 90 & 34 & Never & 0 pos & None & DM2 \\
\hline 3 & $\mathrm{~F}$ & 48 & 63 & 23 & Never & 0 pos & None & None \\
\hline 4 & M & 57 & 96 & 29 & Never & 0 pos & None & None \\
\hline 5 & $\mathrm{~F}$ & 38 & 99 & 35 & Never & 0 pos & Influenza B & DM2, HTN, GERD \\
\hline 8 & M & 74 & 84 & 27 & Never & A pos & VAP: MSSA and GAS & DM2, HTN, CKD \\
\hline 9 & $\mathrm{~F}$ & 55 & 73 & 26 & Never & 0 pos & None & None \\
\hline 10 & $\mathrm{~F}$ & 19 & 113 & 49 & Never & 0 pos & Enterococcus BSI & None \\
\hline 11 & $\mathrm{~F}$ & 22 & 91 & 40 & Never & 0 pos & None & Asthma \\
\hline 12 & $\mathrm{~F}$ & 46 & 65.8 & 24.9 & Never & 0 pos & None & None \\
\hline 17 & $\mathrm{~F}$ & 54 & 79 & 30 & Never & 0 pos & None & HTN \\
\hline 18 & $M$ & 56 & 102 & 40 & Never & 0 pos & None & HTN, HLP \\
\hline 19 & $M$ & 60 & 81.6 & 32 & Never & 0 pos & None & DM2, HLD \\
\hline 20 & $\mathrm{~F}$ & 77 & 95 & 36 & Never & 0 pos & None & HTN, DM2 \\
\hline 21 & $\mathrm{~F}$ & 60 & 65 & 23 & Never & 0 neg & None & None \\
\hline 22 & $\mathrm{~F}$ & 77 & 86.5 & 29.8 & Never & A pos & GAS & Atrial fibrillation, DM2, HLD \\
\hline 23 & M & 60 & 85 & 30.4 & Never & 0 pos & None & DM2, HLD, HTN \\
\hline 24 & M & 54 & 72 & 25 & Never & B pos & None & HLD \\
\hline 25 & M & 50 & 58 & 22.6 & Never & B pos & None & None \\
\hline
\end{tabular}

F, female; M, male; BMI, body mass index; BSI, bloodstream infection; CKD, chronic kidney disease; COVID-19, coronavirus disease 2019; DM2, diabetes mellitus type 2; GAS, group A Streptococcus; GERD, gastrointestinal reflux disease; HLD, hyperlipidemia; HLP, hyperlipidemia; HTN, hypertension; MSSA, methicillinsusceptible Staphylococcus aureus; neg, negative; None, no infection identified; PNA, pneumonia; pos, positive; VAP, ventilator-associated pneumonia.

morbilliform rash 1 day after transfusion that lasted for several days. Punch biopsy findings were compatible with an exanthematous drug eruption, and classic histologic findings of serum sickness (leukocytoclasic vasculitis) were not seen. Two patients developed deep vein thrombosis 4 and 8 days after transfusion, and one patient developed a deep vein thrombosis and a pulmonary embolism 4 days after transfusion. The observed thrombotic complications are consistent with findings reported for COVID-19 patients. ${ }^{28}$ The secondary end point was an improvement in the modified six-point World Health Organization ordinal scale at day 14 after transfusion, including discharge from the hospital (Supplemental Table S2). At day 7 after transfusion, 9 patients (36\%) improved from baseline, $13(52 \%)$ had no change, and 3 deteriorated (Figure 2). Seven of the nine improved patients (28\%) had been discharged. By day 14 after transfusion, 19 patients (76\%) improved from baseline: an additional four patients were discharged, eight patients improved from baseline, three patients remained unchanged, three had deteriorated, and one patient died from a condition not caused by plasma transfusion (Figure 2 and Supplemental Table S2). The average overall length of hospital stay was 14.3 days (range, 2 to 25 days). The average post-transfusion length of hospital stay was 11 days (range, 1 to 21 days) (Table 3).

\section{Laboratory Results}

Laboratory results were assessed for parameters associated with inflammation and liver function. The median value for C-reactive protein decreased in our cohort from 14.66 $\mathrm{mg} / \mathrm{dL}$ at day 0 to 2.9 and $0.45 \mathrm{mg} / \mathrm{dL}$ at days 7 and 14 after transfusion, respectively (Table 4). There was a trend toward increasing ferritin by day 3 , which tended to decrease by day 7 . No significant increases in liver enzymes were noted (Table 4 and Supplemental Table S3).

\section{Viral Genome Sequencing of SARS-CoV-2 Strains from Recipients and Donors}

A recent analysis of the genomic heterogeneity of the SARSCoV-2 virus strains circulating in Houston early in the pandemic showed that the predominant clades isolated were A2a, B and B1. ${ }^{29}$ Amino acid polymorphisms, especially in the spike protein, can potentially alter the character of the antibody response and virulence profile of the virus. ${ }^{23,30-32}$ Therefore, the genomes of the SARS-CoV-2 virus strains infecting donors and recipients were sequenced to assess the magnitude of nucleotide and amino acid mismatch between the viral genotype of donors and plasma recipients. Of the 34 patients and donors, all plasma recipient genotypes and four 
Table 2 Characteristics of Convalescent Plasma Donors

\begin{tabular}{|c|c|c|c|c|c|c|c|c|c|}
\hline Donor & $\begin{array}{l}\text { Age, } \\
\text { years }\end{array}$ & Sex & $\begin{array}{l}\text { Blood } \\
\text { type }\end{array}$ & $\begin{array}{l}\text { Symptom } \\
\text { start date }\end{array}$ & $\begin{array}{l}\text { Positive } \\
\text { test date }\end{array}$ & Hospitalized & $\begin{array}{l}\text { Symptoms } \\
\text { resolved }\end{array}$ & Plasma collected date(s) & $\begin{array}{l}\text { Symptom } \\
\text { resolution to } \\
\text { first donation, } \\
\text { days }\end{array}$ \\
\hline 1 & 44 & M & 0 pos & $3 / 7 / 20$ & $3 / 14 / 20$ & No & $3 / 10 / 20$ & $3 / 27 / 20,3 / 31 / 20,4 / 3 / 20,4 / 7 / 20$ & 17 \\
\hline 2 & 36 & M & 0 pos & $3 / 6 / 20$ & $3 / 12 / 20$ & No & $3 / 13 / 20$ & $3 / 31 / 20,4 / 3 / 20,4 / 8 / 20$ & 19 \\
\hline 3 & 67 & $\mathrm{~F}$ & A pos & $3 / 6 / 20$ & $3 / 17 / 20$ & No & $3 / 17 / 20$ & $4 / 3 / 20$ & 17 \\
\hline 6 & 41 & $\mathrm{~F}$ & 0 pos & $3 / 21 / 20$ & $3 / 23 / 20$ & No & $3 / 24 / 20$ & $4 / 9 / 20$ & 16 \\
\hline 7 & 54 & $\mathrm{~F}$ & A pos & $3 / 18 / 20$ & $3 / 20 / 20$ & No & $3 / 19 / 20$ & $4 / 7 / 20$ & 19 \\
\hline 8 & 61 & M & A pos & $3 / 8 / 20$ & $3 / 16 / 20$ & Yes & $3 / 22 / 20$ & $4 / 10 / 20$ & 19 \\
\hline 9 & 23 & M & B pos & $3 / 13 / 20$ & $3 / 17 / 20$ & No & $3 / 25 / 20$ & $4 / 13 / 20$ & 19 \\
\hline
\end{tabular}

$F$, female; $M$, male; pos, positive.

donor genotypes were analyzed. Overall, there were few polymorphisms in the sequenced viruses, and there was no correlation between infecting strains and disease severity (Supplemental Figure S1). Analysis of the first four donors found that, in general, donor and recipient $S$ proteins matched when their SARS-CoV-2 isolates were from the same clade (Supplemental Figure S1). This is primarily a result of a D614G amino acid change in $\mathrm{S}$ protein that defines the clade A2a. ${ }^{29,33}$ However, there are at least three instances of an additional amino acid change in the $S 2$ domain of the $S$ protein, ${ }^{23,31,32}$ one in a donor (M731I) and two in recipients (S967R and L1203F) (Supplemental Figure S1).

\section{Discussion}

The current study was performed to evaluate the safety and potential benefit of transfusing convalescent plasma to patients with severe COVID-19 disease. To date, this is the largest cohort assessed for outcomes pertaining to convalescent

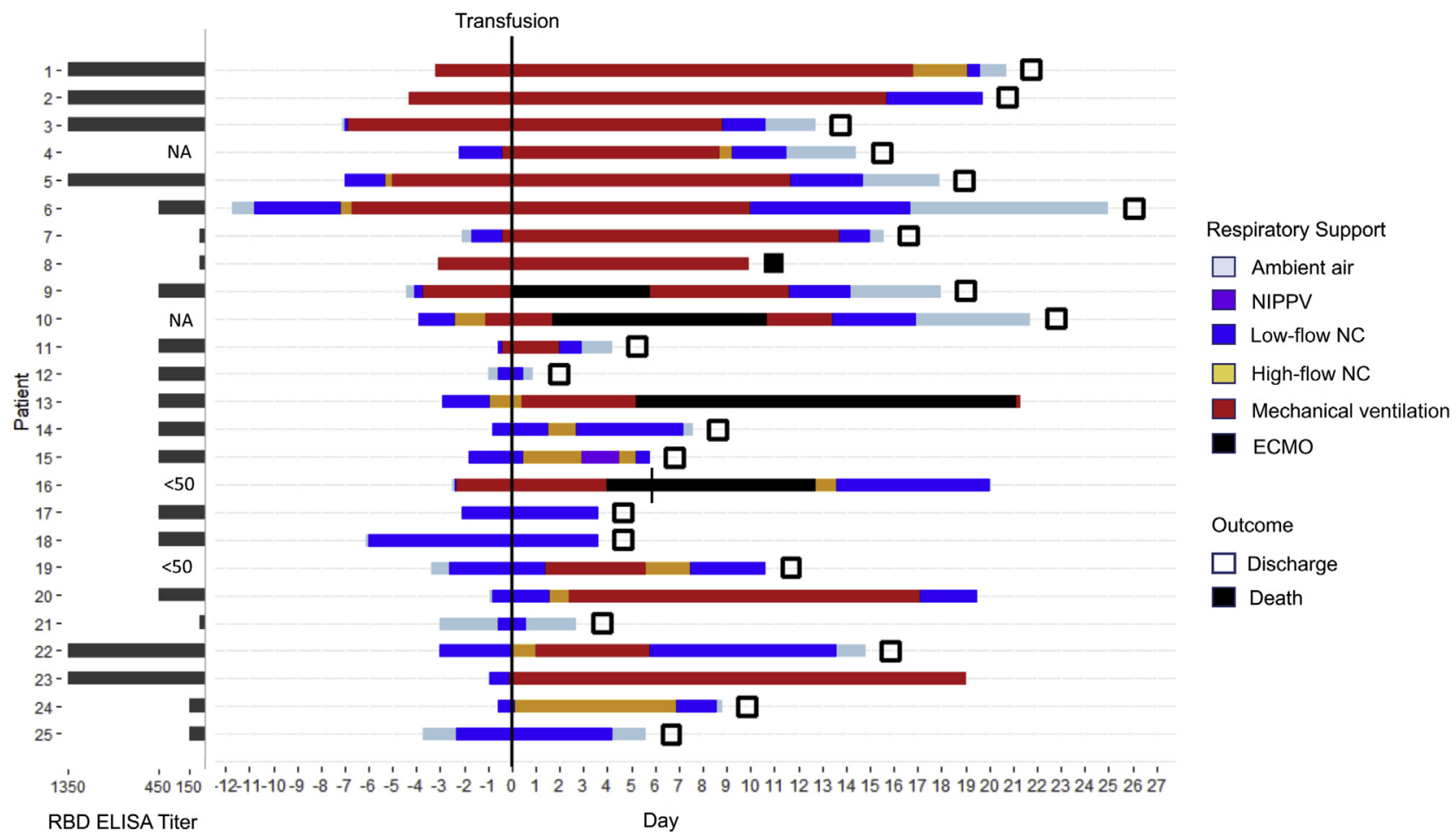

Figure 1 Respiratory support status, clinical score, patient outcomes (discharge/death), and receptor binding domain (RBD) titer of transfused plasma in a 25-patient cohort. Respiratory support requirements for the duration of hospitalization are color coded per the key. Discharge or death is indicated by open or closed squares, respectively. Patients without a square symbol were still hospitalized at day 14 after transfusion (study end point). Patient 16 was given a second transfusion on day 6 , indicated by a vertical line. The convalescent plasma titers for the RBD domain of the severe acute respiratory syndrome coronavirus 2 spike protein are indicated to the left. ECMO, extracorporeal membrane oxygen; ELISA, enzyme-linked immunosorbent assay; NA, not available; NC, nasal cannula; NIPPV, noninvasive, positive-pressure ventilation. 
Table 3 Disease Course and Additional Treatments of Patients Receiving Convalescent Plasma

\begin{tabular}{|c|c|c|c|c|c|c|c|c|}
\hline $\begin{array}{l}\text { Patient } \\
\text { No. }\end{array}$ & $\begin{array}{l}\text { Symptom } \\
\text { onset to } \\
\text { admission, } \\
\text { days }\end{array}$ & $\begin{array}{l}\text { Symptom } \\
\text { onset } \\
\text { to positive } \\
\text { SARS test, } \\
\text { days }\end{array}$ & $\begin{array}{l}\text { Admission to } \\
\text { transfusion, } \\
\text { days }\end{array}$ & $\begin{array}{l}\text { Complications } \\
\text { before } \\
\text { transfusion }\end{array}$ & $\begin{array}{l}\text { Anti-inflammatory } \\
\text { treatments }\end{array}$ & $\begin{array}{l}\text { Antiviral } \\
\text { treatments }\end{array}$ & $\begin{array}{l}\text { Length of } \\
\text { hospital } \\
\text { stay, } \\
\text { days }\end{array}$ & $\begin{array}{l}\text { Post-transfusion } \\
\text { length } \\
\text { of hospital } \\
\text { stay, } \\
\text { days }\end{array}$ \\
\hline 1 & 7 & 3 & 1 & ARDS & Tocilizumab & $\mathrm{HCQ}, \mathrm{RBV}$ & 24 & 21 \\
\hline 2 & 7 & 9 & 4 & ARDS, CRRT & Interferon, steroids & $\mathrm{HCQ}, \mathrm{AZM}, \mathrm{RBV}$ & 24 & 20 \\
\hline 5 & 3 & 4 & 7 & ARDS & None & $\mathrm{HCQ}, \mathrm{AZM}, \mathrm{RBV}$ & 25 & 18 \\
\hline 6 & 3 & 4 & 13 & ARDS & Tocilizumab & $\mathrm{HCQ}, \mathrm{AZM}, \mathrm{RBV}$ & 37 & NA \\
\hline 7 & 3 & 3 & 2 & ARDS & Tocilizumab & $\mathrm{HCQ}, \mathrm{LPVr}$ & 20 & 16 \\
\hline 8 & 4 & 5 & 3 & ARDS & Steroids & $\mathrm{HCQ}, \mathrm{RBV}, \mathrm{LPVr}$ & 13 & 10 \\
\hline 9 & 4 & 4 & 4 & $\begin{array}{r}\text { ARDS, CRRT, } \\
\text { ECMO (VV) }\end{array}$ & Tocilizumab, steroids & $\mathrm{HCQ}, \mathrm{RBV}$ & 22 & 18 \\
\hline 12 & 10 & 6 & 2 & None & None & $\mathrm{HCQ}, \mathrm{AZM}$ & 2 & 1 \\
\hline 13 & 5 & 6 & 3 & None & Tocilizumab & $\mathrm{HCQ}, \mathrm{AZM}, \mathrm{RBV}$ & NA & NA \\
\hline 14 & 12 & 6 & 1 & None & Tocilizumab, steroids & $\mathrm{HCQ}, \mathrm{AZM}, \mathrm{RBV}$ & 9 & 8 \\
\hline 15 & 7 & 8 & 2 & None & None & $\mathrm{HCQ}, \mathrm{AZM}, \mathrm{RBV}$ & 8 & 6 \\
\hline 16 & 8 & 3 & 2 & ARDS & Tocilizumab, steroids & $\mathrm{HCQ}, \mathrm{AZM}, \mathrm{RBV}$ & NA & NA \\
\hline 17 & 4 & 4 & 2 & None & None & $\mathrm{HCQ}, \mathrm{AZM}$ & 6 & 4 \\
\hline 18 & 8 & 8 & 6 & None & None & $\mathrm{HCQ}, \mathrm{AZM}$ & 10 & 4 \\
\hline 19 & 6 & 6 & 3 & None & Tocilizumab & $\mathrm{HCQ}, \mathrm{AZM}$ & 14 & 11 \\
\hline 20 & 3 & 4 & 1 & None & None & $\begin{array}{l}\mathrm{HCQ}, \mathrm{RBV}, \\
\text { AZM, remdesivir }\end{array}$ & NA & NA \\
\hline 21 & 8 & 8 & 3 & None & None & $\mathrm{HCQ}, \mathrm{RBV}$ & 6 & 3 \\
\hline
\end{tabular}

ARDS, acute respiratory distress syndrome; AZM, azithromycin; CRRT, cardiac rapid response team; ECMO (VV), extracorporeal mechanical oxygenation (venovenous); $\mathrm{HCQ}$, hydroxychloroquine; LPVr, lopinavir/ritonavir; NA, still hospitalized at day 14 after transfusion (study end point); RBV, ribavirin; SARS, severe acute respiratory syndrome.

plasma transfusion for COVID-19. Of the 25 patients, 9 had improvement by day 7 , and an additional 12 patients (for a total of 19) had improvement by day 14. as assessed by discharge or at least a one-point improvement on a modified clinical scale. Several case studies investigating the use of convalescent plasma to treat severe COVID-19 have recently been published, ${ }^{17-21}$ and the overall findings presented herein are consistent with these reports.

Convalescent plasma therapy has been administered on the frontlines during emergencies, and the need for controlled clinical trials to determine its therapeutic efficacy has been recognized. ${ }^{13,14,18,34,35}$ The timing of the transfusion after symptom onset, the number of transfusions, the volume and its adjustment on the basis of body mass index, donor antibody titers, and other parameters need to be evaluated to optimize this therapy. For example, some studies have observed that the sooner after the onset of symptoms that the transfusion was administered, the better the outcomes. ${ }^{13,14,35}$ Variability existed among our cohort with respect to symptom onset and severity of illness.
The anti-SARS-CoV-2 anti-spike protein IgG titers varied significantly among individual donors, as assessed by ELISA (Supplemental Table S1). Early in the study period, ELISA titers were not available, and thus, transfusions were given solely on the basis of ABO compatibility. Among the five patients who received plasma from a donor with an anti-RBD $\operatorname{IgG}$ titer of $\leq 50$, one is deceased, and one was placed on ECMO. The patient placed on ECMO received a second dose of convalescent plasma confirmed to have high IgG titer before transfusion. The patient was eventually extubated and weaned off ECMO. Regardless, at this time, no clear correlation between ELISA IgG titer and patient outcomes can be established in this small patient cohort. In addition, more studies are needed to better understand why donors present with a range of anti-spike antibody titers, and whether there is a correlation between donor disease presentation and antibody titers. Additional studies are underway to better understand the correlation between anti-SARS-CoV-2 antibody titers and virus neutralization. 


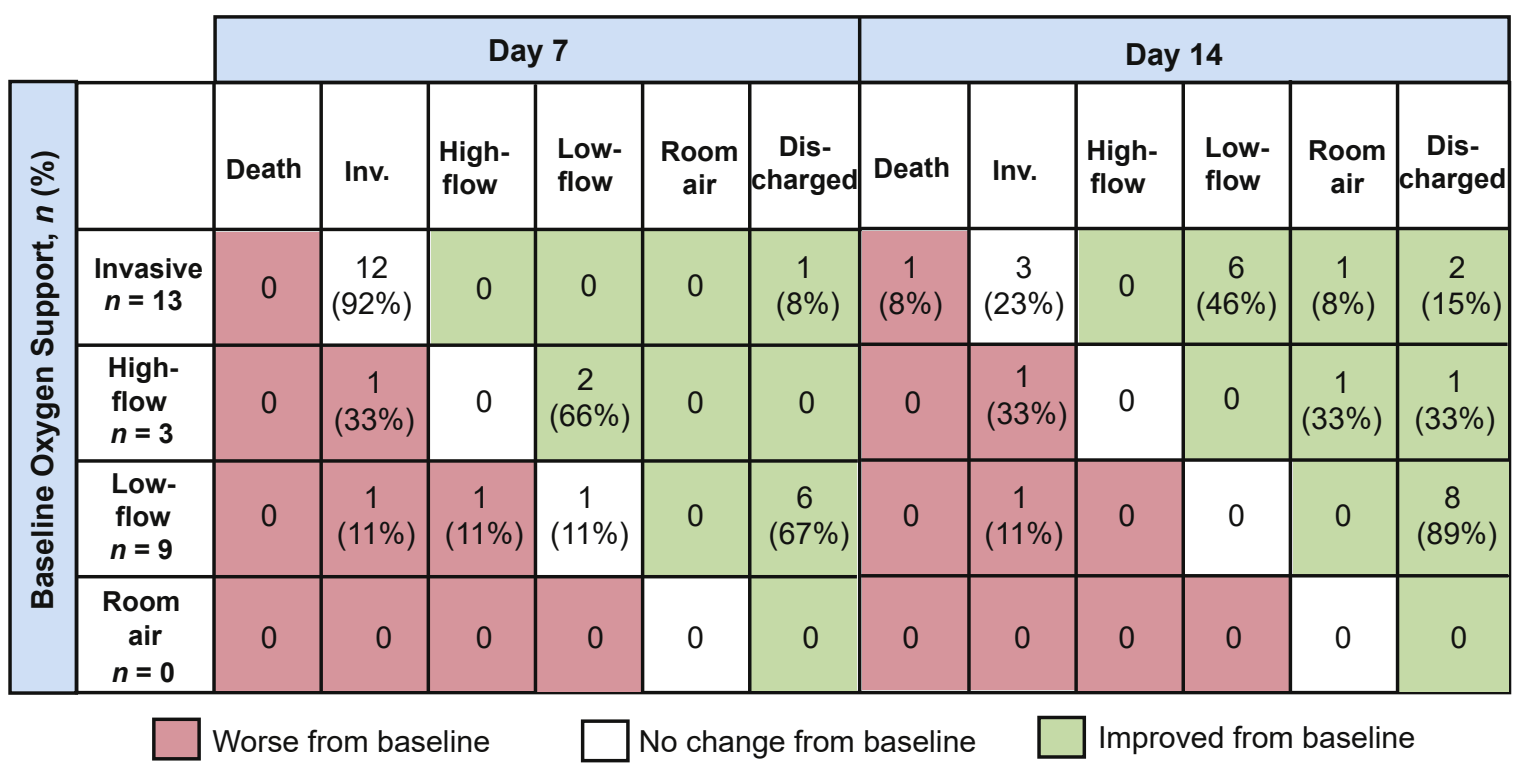

Figure 2 Clinical outcomes at days 7 and 14 after transfusion. Distribution of patients on low-flow, high-flow, invasive, or no oxygen support at days 0 (day of transfusion), 7, and 14. By day 7 after transfusion, 36\% (9/25) of patients had improved from baseline; $76 \%$ (19/25) of patients improved by day 14 after transfusion. Inv., Invasive.

The results from this study support the existing data from the COVID-19 literature that point to underlying medical conditions, such as obesity, type 2 diabetes, and hypertension, playing a large role in patients' COVID-19 disease course and outcomes. ${ }^{36-38}$ Of transfused patients in this study, 68\% (17/25) had a body mass index in the obese category and $84 \%$ were considered overweight.

A confounding variable in many convalescent plasma studies is the addition of other treatment regimens, such as antivirals and anti-inflammatory compounds. Adjunct therapies hinder the ability to draw definitive conclusions regarding the contribution of the convalescent plasma. In the current study, all 25 patients received hydroxychloroquine and azithromycin, as these were reported to have beneficial effects early in the pandemic. ${ }^{10}$ Subsequent larger and more controlled studies determined that this combination has no benefits to patients and, in fact, could be harmful. ${ }^{11}$ Many $(68 \%)$ of our patients were also administered oral ribavirin. Despite inconclusive data on ribavirin's efficacy in the treatment of SARS during the 2003 epidemic, ${ }^{39}$ proven safety and ready availability supported its use in the treatment of our COVID-19 patients. Two patients received remdesivir, which was recently shown to modestly reduce recovery time (NIH, https://www.niaid.nih.gov/news-events/ nih-clinical-trial-shows-remdesivir-accelerates-recoveryadvanced-covid-19, last accessed May 5, 2020). ${ }^{9}$ Antiinflammatory compounds, such as the IL-6 inhibitor tocilizumab and methylprednisolone, were administered per institutional protocols within 5 days of the plasma transfusion to $72 \%$ of our cohort. Tocilizumab was recently shown to reduce mortality in a retrospective analysis of 20 severe COVID-19 patients. ${ }^{40}$ Because convalescent plasma therapy is typically performed in emergency situations for the ill, it is difficult to assess its benefits as a stand-alone treatment. A blinded, randomized controlled trial is currently being considered.

The patient outcomes in the current study are similar to those recently published describing treating COVID-19 patients with remdesivir on a compassionate-use basis. ${ }^{9}$ In that review, patients were prescribed a 10-day course of remdesivir, with follow-up for 28 days or until discharge or death. Both study cohorts included patients who required invasive ventilation, including 35 of $53(66 \%)$ of remdesivir patients compared with 17 of 25 (68\%) of the patients in this study. Clinical improvement was less frequent among patients who received invasive ventilation at any time or were aged $\geq 70$ years. In the remdesivir study, 36 of 53 patients (68\%) showed clinical improvement at follow-up (median time to follow-up, 18 days), whereas 19 of 25 patients (76\%) receiving convalescent plasma improved by day 14 after transfusion. These data suggest that treatment with convalescent plasma and remdesivir resulted in similar outcomes among patients on the basis of oxygenation requirements and age. The mortality difference between the cohorts cannot be compared as the remdesivir cohort represented an older population (median age, 64 years, versus 51 years in the current study), where the risk of death was greater at baseline. Delays in obtaining remdesivir on a compassionate-use basis (12 days from symptom onset) may have artificially extended the cohort's opportunity to demonstrate clinical improvement and does not reflect the eligibility criteria for any ongoing clinical trials (World Health Organization, https://www. who.int/emergencies/diseases/novel-coronavirus-2019/globalresearch-on-novel-coronavirus-2019-ncov/solidarity-clinicaltrial-for-covid-19-treatments, last accessed May 5, 2020; NIH, https://clinicaltrials.gov/ct2/show/NCT04292899, last 
Table 4 Median Laboratory Values of Plasma Recipients at Days 0, 7, and 14 after Transfusion

\begin{tabular}{llll}
\hline & \multicolumn{3}{l}{ Median values } \\
\cline { 2 - 4 } Laboratory test (normal range) & Day 0 & Day 7 & Day 14 \\
\hline CRP $(0-0.5 \mathrm{mg} / \mathrm{dL})$ & 14.66 & 2.9 & 0.45 \\
WBC count $(4.5-11 \mathrm{k} / \mu \mathrm{L})$ & 10.9 & 11.3 & 13.1 \\
LDH $(87-225 \mathrm{U} / \mathrm{L})$ & 380 & 394 & 305 \\
ALT $(5-50 \mathrm{U} / \mathrm{L})$ & 38 & 60.5 & 47 \\
AST $(10-35 \mathrm{U} / \mathrm{L})$ & 51 & 41 & 32 \\
Ferritin $(13-150 \mathrm{ng} / \mathrm{mL})$ & 878 & 1633.5 & 718 \\
Total bilirubin $(0-1.2 \mathrm{mg} / \mathrm{dL})$ & 0.4 & 0.75 & 0.9 \\
\hline
\end{tabular}

ALT, alanine aminotransferase; AST, aspartate aminotransferase; CRP, C-reactive protein; k, 1000; LDH, lactate dehydrogenase; WBC, white blood cell.

accessed May 5, 2020; NIH, https://clinicaltrials.gov/ct2/ show/NCT04280705, last accessed May 5, 2020). Clinical outcomes data to inform timing of therapeutic interventions, like remdesivir or convalescent plasma, are lacking.

The genomes of the infecting SARS-CoV-2 strain from both the donors and recipients were analyzed. One could conceive of a situation in which the donor genotype of the SARS-CoV-2 infecting strain was matched with the genotype of the patient's strain to maximize potential immune benefit. This study found few differences in the inferred amino acid sequences of the plasma donor and recipient strains and no association between disease severity and infecting strain genotype.

Most of the donors and plasma recipients in the current study had type O blood $(25 / 34,74 \%)$. Initial donors, who donated repeatedly, were blood type $\mathrm{O}$. Because $\mathrm{ABO}$ compatibility was a requirement for recipient selection early in the study, many of our early recipients were also type O. Zhao et $\mathrm{al}^{41}$ have reported that of the 2173 patients analyzed in their study of COVID-19 patients in China, most had type A blood. More studies are needed to determine if this association holds true in geographically distinct areas of infection. Regardless, our data do not reflect a higher rate of blood type A in COVID-19 patients.

\section{Limitations}

As with the great majority of the studies using convalescent plasma to treat severe infections, this study has several important limitations. First, the study was a small case series and no control group was included. Thus, it is not clear if the 25 patients given convalescent plasma would have improved without this treatment. Second, all patients were treated with multiple other medications, including antiviral and anti-inflammatory agents. Thus, we cannot conclude that the patient outcomes were due solely to administration of convalescent plasma. Third, 24 of the 25 patients received only one transfusion of plasma. Whether treatment with multiple transfusions on $\geq 1$ day would be a more effective regimen is not clear. An expanded donor pool providing higher-titer convalescent plasma would allow for dose escalation studies. Fourth, many patients had severe COVID-19 disease. It is possible that transfusion of convalescent plasma earlier in the course of disease or in patients with less severe symptoms would be a better approach. Fifth, plasma donors in the current study had a range of anti-S protein IgG titers. Several patients were transfused with plasma with low titer of anti-S protein antibody. Sixth, the small number of patients treated, coupled with the experimental design, did not permit us to determine if this therapy significantly reduces mortality or other measures of disease outcome. Finally, although this study assessed outcomes at days 7 and 14 after transfusion, at the time of this writing, all but two of the surviving patients who were intubated had been extubated. Similarly, all patients that were on ECMO had been weaned, and 20 of the 25 patients had been discharged.

\section{Conclusion}

Outcomes from this case series of 25 patients indicate that administration of convalescent plasma is a safe treatment option for those with severe COVID-19 disease.

\section{Acknowledgments}

We thank our many volunteer plasma donors for their time, their gift, and their solidarity; Drs. Jessica Thomas and Zejuan Li, Erika Walker, the molecular technologists, and the many labor pool volunteers in the Molecular Diagnostics Laboratory for dedication to patient care; the many donor center and blood bank phlebotomists and technologists for dedication to donor and blood safety; Kathryn Stockbauer for editorial assistance; Brandi Robinson, Harrold Cano, and Cory Romero for technical assistance; Dr. Susan Miller and Mary Clancy for advice; Aramco Americas for support of Houston Methodist's convalescent plasma program for the treatment of COVID-19; Drs. Marc Boom and Dirk Sostman for support; many generous Houston philanthropists for support, including anonymous, Ann and John Bookout III, Carolyn and John Bookout, Ting Tsung and Wei Fong Chao Foundation, Ann and Leslie Doggett, Freeport LNG, the Hearst Foundations, Jerold B. Katz Foundation, C. James and Carole Walter Looke, Diane and David Modesett, the Sherman Foundation, and Paula and Joseph C. "Rusty" Walter III; Dr. Jason S. McLellan (The University of Texas at Austin) for providing the monoclonal antibody CR3022 and the spike protein expression vectors; the members of the Center for Systems and Synthetic Biology at the University of Texas at Austin for technical assistance; and Tom Anderson and Terumo BCT for supplying blood collection devices and supplies. 


\section{Supplemental Data}

Supplemental material for this article can be found at http://doi.org/10.1016/j.ajpath.2020.05.014.

\section{References}

1. Huang C, Wang Y, Li X, Ren L, Zhao J, Hu Y, Zhang L, Fan G, Xu J, Gu X, Cheng Z, Yu T, Xia J, Wei Y, Wu W, Xie X, Yin W, Li H, Liu M, Xiao Y, Gao H, Guo L, Xie J, Wang G, Jiang R, Gao Z, Jin Q, Wang J, Cao B: Clinical features of patients infected with 2019 novel coronavirus in Wuhan, China. Lancet 2020, 395:497-506

2. Li R, Pei S, Chen B, Song Y, Zhang T, Yang W, Shaman J: Substantial undocumented infection facilitates the rapid dissemination of novel coronavirus (SARS-CoV-2). Science 2020, 368:489-493

3. Wang C, Horby PW, Hayden FG, Gao GF: A novel coronavirus outbreak of global health concern. Lancet 2020, 395:470-473

4. Caly L, Druce J, Roberts J, Bond K, Tran T, Kostecki R, Yoga Y, Naughton W, Taiaroa G, Seemann T, Schultz MB, Howden BP, Korman TM, Lewin SR, Williamson DA, Catton MG: Isolation and rapid sharing of the 2019 novel coronavirus (SARS-CoV-2) from the first patient diagnosed with COVID-19 in Australia. Med J Aust 2020, 212:459-462

5. Ghosal S, Sengupta S, Majumder M, Sinha B: Linear regression analysis to predict the number of deaths in India due to SARS-CoV-2 at 6 weeks from day 0 (100 cases - March 14th 2020). Diabetes Metab Syndr 2020, 14:311-315

6. Gudbjartsson DF, Helgason A, Jonsson H, Magnusson OT, Melsted P, Norddahl GL, et al: Spread of SARS-CoV-2 in the Icelandic population. N Engl J Med 2020, 382:2302-2315

7. Hodcroft EB: Preliminary case report on the SARS-CoV-2 cluster in the UK, France, and Spain. Swiss Med Wkly 2020, 150:w20212

8. Piva S, Filippini M, Turla F, Cattaneo S, Margola A, De Fulviis S, Nardiello I, Beretta A, Ferrari L, Trotta R, Erbici G, Foca E, Castelli F, Rasulo F, Lanspa MJ, Latronico N: Clinical presentation and initial management critically ill patients with severe acute respiratory syndrome coronavirus 2 (SARS-CoV-2) infection in Brescia, Italy. J Crit Care 2020, 58:29-33

9. Grein J, Ohmagari N, Shin D, Diaz G, Asperges E, Castagna A, et al: Compassionate use of remdesivir for patients with severe Covid-19. N Engl J Med 2020, 382:2327-2336

10. Gautret P, Lagier JC, Parola P, Hoang VT, Meddeb L, Mailhe M, Doudier B, Courjon J, Giordanengo V, Vieira VE, Dupont HT, Honore S, Colson P, Chabriere E, La Scola B, Rolain JM, Brouqui P, Raoult D: Hydroxychloroquine and azithromycin as a treatment of COVID-19: results of an open-label non-randomized clinical trial. Int J Antimicrob Agents 2020, [Epub ahead of print] doi: 10.1016/j. ijantimicag.2020.105949

11. Magagnoli J, Narendran S, Pereira F, Cummings T, Hardin JW, Sutton SS, Ambati J: Outcomes of hydroxychloroquine usage in United States veterans hospitalized with Covid-19. medRxiv 2020, [Epub] doi: 10.1101/2020.04.16.20065920

12. Luke TC, Kilbane EM, Jackson JL, Hoffman SL: Meta-analysis: convalescent blood products for Spanish influenza pneumonia: a future H5N1 treatment? Ann Intern Med 2006, 145:599-609

13. Soo YO, Cheng Y, Wong R, Hui DS, Lee CK, Tsang KK, Ng MH, Chan P, Cheng G, Sung JJ: Retrospective comparison of convalescent plasma with continuing high-dose methylprednisolone treatment in SARS patients. Clin Microbiol Infect 2004, 10:676-678

14. Cheng Y, Wong R, Soo YO, Wong WS, Lee CK, Ng MH, Chan P, Wong KC, Leung CB, Cheng G: Use of convalescent plasma therapy in SARS patients in Hong Kong. Eur J Clin Microbiol Infect Dis 2005, 24:44-46

15. Hung IF, To KK, Lee CK, Lee KL, Chan K, Yan WW, Liu R, Watt CL, Chan WM, Lai KY, Koo CK, Buckley T, Chow FL,
Wong KK, Chan HS, Ching CK, Tang BS, Lau CC, Li IW, Liu SH, Chan KH, Lin CK, Yuen KY: Convalescent plasma treatment reduced mortality in patients with severe pandemic influenza A (H1N1) 2009 virus infection. Clin Infect Dis 2011, 52:447-456

16. van Griensven J, Edwards $T$, de Lamballerie $X$, Semple $M G$, Gallian P, Baize S, Horby PW, Raoul H, Magassouba N, Antierens A, Lomas C, Faye O, Sall AA, Fransen K, Buyze J, Ravinetto R, Tiberghien P, Claeys Y, De Crop M, Lynen L, Bah EI, Smith PG, Delamou A, De Weggheleire A, Haba N: Ebola-Tx Consortium: Evaluation of convalescent plasma for Ebola virus disease in Guinea. N Engl J Med 2016, 374:33-42

17. Duan K, Liu B, Li C, Zhang H, Yu T, Qu J, et al: Effectiveness of convalescent plasma therapy in severe COVID-19 patients. Proc Natl Acad Sci U S A 2020, 117:9490-9496

18. Shen C, Wang Z, Zhao F, Yang Y, Li J, Yuan J, Wang F, Li D, Yang M, Xing L, Wei J, Xiao H, Yang Y, Qu J, Qing L, Chen L, Xu Z, Peng L, Li Y, Zheng H, Chen F, Huang K, Jiang Y, Liu D, Zhang Z, Liu Y, Liu L: Treatment of 5 critically ill patients with COVID-19 with convalescent plasma. JAMA 2020, 323:1582-1589

19. Ye M, Fu D, Ren Y, Wang F, Wang D, Zhang F, Xia X, Lv T: Treatment with convalescent plasma for COVID-19 patients in Wuhan, China. J Med Virol 2020, [Epub ahead of print] doi: 10.1002/ jmv. 25882

20. Zhang B, Liu S, Tan T, Huang W, Dong Y, Chen L, Chen Q, Zhang L, Zhong Q, Zhang X, Zou Y, Zhang S: Treatment with convalescent plasma for critically ill patients with SARS-CoV-2 infection. Chest 2020, 158:e9-e13

21. Zeng QL, Yu ZJ, Gou JJ, Li GM, Ma SH, Zhang GF, Xu JH, Lin WB, Cui GL, Zhang MM, Li C, Wang ZS, Zhang ZH, Liu ZS: Effect of convalescent plasma therapy on viral shedding and survival in COVID-19 patients. J Infect Dis 2020, 222:38-43

22. Corman VM, Landt O, Kaiser M, Molenkamp R, Meijer A, Chu DKW, Bleicker T, Brünink S, Schneider J, Schmidt ML, Mulders D, Haagmans BL, van der Veer B, van den Brink S, Wijsman L, Goderski G, Romette JL, Ellis J, Zambon M, Peiris M, Goossens H, Reusken C, Koopmans MPG, Drosten C: Detection of 2019 novel coronavirus (2019-nCoV) by real-time RT-PCR. Euro Surveill 2020, 25:2000045

23. Wrapp D, Wang N, Corbett KS, Goldsmith JA, Hsieh CL, Abiona O, Graham BS, McLellan JS: Cryo-EM structure of the 2019-nCoV spike in the prefusion conformation. Science 2020, 367:1260-1263

24. ter Meulen J, van den Brink EN, Poon LL, Marissen WE, Leung CS, Cox F, Cheung CY, Bakker AQ, Bogaards JA, van Deventer E, Preiser W, Doerr HW, Chow VT, de Kruif J, Peiris JS, Goudsmit J: Human monoclonal antibody combination against SARS coronavirus: synergy and coverage of escape mutants. PLoS Med 2006, 3:e237

25. Tian X, Li C, Huang A, Xia S, Lu S, Shi Z, Lu L, Jiang S, Yang Z, Wu Y, Ying T: Potent binding of 2019 novel coronavirus spike protein by a SARS coronavirus-specific human monoclonal antibody. Emerg Microbes Infect 2020, 9:382-385

26. Stamatakis A: RAxML version 8: a tool for phylogenetic analysis and post-analysis of large phylogenies. Bioinformatics (Oxford, England) 2014, 30:1312-1313

27. Wu C, Chen X, Cai Y, Xia J, Zhou X, Xu S, Huang H, Zhang L, Zhou X, Du C, Zhang Y, Song J, Wang S, Chao Y, Yang Z, Xu J, Zhou X, Chen D, Xiong W, Xu L, Zhou F, Jiang J, Bai C, Zheng J, Song Y: Risk factors associated with acute respiratory distress syndrome and death in patients with coronavirus disease 2019 pneumonia in Wuhan, China. JAMA Intern Med 2020, 180:1-11

28. Klok FA, Kruip M, van der Meer NJM, Arbous MS, Gommers D, Kant KM, Kaptein FHJ, van Paassen J, Stals MAM, Huisman MV, Endeman $\mathrm{H}$ : Incidence of thrombotic complications in critically ill ICU patients with COVID-19. Thromb Res 2020, 191:145-147

29. Long SW, Olsen RJ, Christensen PA, Bernard DW, Davis JJ, Shukla M, Nguyen M, Saavedra MO, Cantu CC, Yerramilli P, Pruitt L, Subedi S, Hendrickson H, Eskandari G, Kumaraswami M, McLellan JS, Musser JM: Molecular architecture of early 
dissemination and evolution of the SARS-CoV-2 virus in Metropolitan Houston, Texas. bioRxiv 2020, doi: 2020.05.01.072652.

30. Brufsky A: Distinct viral clades of SARS-CoV-2: implications for modeling of viral spread. J Med Virol 2020, [Epub ahead of print] doi: 10.1002/jmv.25902

31. Walls AC, Park YJ, Tortorici MA, Wall A, McGuire AT, Veesler D: Structure, function, and antigenicity of the SARS-CoV-2 spike glycoprotein. Cell 2020, 181:281-292.e6

32. Wang Q, Zhang Y, Wu L, Niu S, Song C, Zhang Z, Lu G, Qiao C, Hu Y, Yuen KY, Wang Q, Zhou H, Yan J, Qi J: Structural and functional basis of SARS-CoV-2 entry by using human ACE2. Cell 2020, 181:894-904.e9

33. Shu Y, McCauley J: GISAID: global initiative on sharing all influenza data - from vision to reality. Euro Surveill 2017, 22:30494

34. Chen L, Xiong J, Bao L, Shi Y: Convalescent plasma as a potential therapy for COVID-19. Lancet Infect Dis 2020, 20:398-400

35. Mair-Jenkins J, Saavedra-Campos M, Baillie JK, Cleary P, Khaw FM, Lim WS, Makki S, Rooney KD, Nguyen-Van-Tam JS, Beck CR; Convalescent Plasma Study Group: The effectiveness of convalescent plasma and hyperimmune immunoglobulin for the treatment of severe acute respiratory infections of viral etiology: a systematic review and exploratory meta-analysis. J Infect Dis 2015, 211:80-90
36. Deng Y, Liu W, Liu K, Fang YY, Shang J, Zhou L, Wang K, Leng F, Wei S, Chen L, Liu HG: Clinical characteristics of fatal and recovered cases of coronavirus disease 2019 (COVID-19) in Wuhan, China: a retrospective study. Chin Med J (Engl) 2020, 133:1261-1267

37. Emami A, Javanmardi F, Pirbonyeh N, Akbari A: Prevalence of underlying diseases in hospitalized patients with COVID-19: a systematic review and meta-analysis. Arch Acad Emerg Med 2020, 8:e35

38. Yang J, Zheng Y, Gou X, Pu K, Chen Z, Guo Q, Ji R, Wang H, Wang Y, Zhou Y: Prevalence of comorbidities and its effects in coronavirus disease 2019 patients: a systematic review and metaanalysis. Int J Infect Dis 2020, 94:91-95

39. Stockman LJ, Bellamy R, Garner P: SARS: systematic review of treatment effects. PLoS Med 2006, 3:e343

40. Xu X, Han M, Li T, Sun W, Wang D, Fu B, Zhou Y, Zheng X, Yang Y, Li X, Zhang X, Pan A, Wei H: Effective treatment of severe COVID-19 patients with tocilizumab. Proc Natl Acad Sci U S A 2020, 117:10970-10975

41. Zhao J, Yang Y, Huang H, Li D, Gu D, Lu X, Zhang Z, Liu L, Liu T, Liu Y, He Y, Sun B, Wei M, Yang G, Wang X, Zhang L, Zhou X, Xing M, Wang PG: Relationship between the ABO blood group and the COVID-19 susceptibility. medRxiv 2020, [Epub] doi: 2020.03.11. 20031096 